\title{
AgNPs and Ag/C225 Exert Anticancerous Effects via Cell Cycle Regulation and Cytotoxicity Enhancement
}

\author{
Yan Zhang, ${ }^{1}$ Hong Lu, ${ }^{2,3}$ Dahai Yu, ${ }^{2,3}$ and Di Zhao ${ }^{2,3}$ \\ ${ }^{1}$ Department of Clinical Laboratory, Jiangsu Province Hospital, The First Affiliated Hospital of Nanjing Medical University, \\ Nanjing, China \\ ${ }^{2}$ Department of Radiotherapy, Jiangsu Province Hospital of Traditional Chinese Medicine, Affliated Hospital of Nanjing University of \\ Traditional Chinese Medicine, Nanjing, China \\ ${ }^{3}$ Jiangsu Collaborative Innovation Center of Tumor Prevention and Treatment by Traditional Chinese Medicine (TCM), \\ Nanjing University of Chinese Medicine, Nanjing, China
}

Correspondence should be addressed to Di Zhao; 9964307@qq.com

Received 23 December 2016; Accepted 12 April 2017; Published 18 May 2017

Academic Editor: Kimberly Hamad-Schifferli

Copyright (c) 2017 Yan Zhang et al. This is an open access article distributed under the Creative Commons Attribution License, which permits unrestricted use, distribution, and reproduction in any medium, provided the original work is properly cited.

\begin{abstract}
Currently, cancer has become the leading cause of deaths and is a serious threat to human health. Nanotechnology-based medical applications are developing rapidly, especially in anticancer research, as nanomaterials can be retained in the cell after their entry across the cell membrane, making them potential candidates for application in the diagnosis and treatment of tumours. Here, we prepared silver nanoparticles (AgNPs) and silver/cetuximab (Ag/C225) particles of approximately $20 \mathrm{~nm}$ and investigated their inhibitory effect on proliferation of human nasopharyngeal carcinoma cell line CNE and laryngeal carcinoma cell line HEp-2. The MTT assay was used to determine their half-maximal inhibitory concentration (IC50) values. Electron microscopy revealed no obvious morphological differences between the prepared AgNPs and Ag/C225. Treatment of both cell lines with AgNPs and $\mathrm{Ag} / \mathrm{C} 225$ increased the proportion of cells in the G0/G1 stage and decreased the proportion of cells in the S stage. AgNP and $\mathrm{Ag} / \mathrm{C} 225$ treatments increased the expression of apoptotic proteins Bax and P21 and decreased the expression of Bcl-2 in CNE cells, compared to control cells. $\mathrm{Ag} / \mathrm{C} 225$ is internalised by CNE cells, and it enhances X-irradiation-induced cytotoxicity. These results help increase the understanding of the anticancer effect of AgNPs and Ag/C225 and explore their application as radiosensitisers.
\end{abstract}

\section{Introduction}

Nanotechnology has played an increasingly important role in many fields such as life sciences and materials and chemical engineering. Nanotechnology has the potential for wide application in the diagnosis and treatment of tumours [1]. Currently, many nanoparticles are being used in tumour imaging as well as animal and human experiments. In particular, nanosilver is attracting increasing attention from the academic community. Studies on nanosilver toxicity have shown that silver nanoparticles (AgNPs) can lead to DNA damage, causing the retardation of the G2/M stage of the cell cycle [2]. Previous work has confirmed that nanosilver not only has inhibitory effects on tumours but also plays a role in enhancing the inhibiting effect of radioactive rays on tumour cells, when used together with radiation therapy [3].

Radiation therapy is one of the main methods to treat malignant tumours [4], about $70 \%$ of cancer patients have to receive radiation therapy at different stages of treatment. Radiation therapy uses radioactive rays to treat tumours, but it may lead to unbearable adverse reactions due to the inevitable exposure of normal surrounding tissues to the rays. Therefore, much attention has been paid to experimentation with radiation therapy to improve the radiation dose in the area of the tumour, while reducing the dose in the normal tissues nearby. A radiosensitiser is a chemical substance used to selectively enhance the cytotoxic effect of radiation on tumours without affecting normal tissues [5-7]. In vitro and 
in vivo experiments have confirmed the radiosensitisation of cetuximab (C225) in head and neck tumours [8]. Cell cycle analysis revealed that cetuximab and radiation-induced cells accumulate at the radiation-sensitive G2/M stage and the relatively sensitive G1 stage of the cell cycle, resulting in a decrease in the proportion of radiation-resistant $S$ stage cells, thus remarkably increasing the radiation sensitivity of tumours.

To date, few radiosensitisers with low toxicity, high efficiency, and low cost are widely used in clinical settings. This research is aimed at discussing the synthesis and use of new types of composite nanoparticles based on the previously confirmed antitumor effect of AgNPs, thus creating a path toward to the development of novel, targeted radiosensitisers. In this study, we prepared the composite nanoparticle Ag/C225 using the hinge of AgNPs and C225 and treated CNE and HEp-2 cells, in order to evaluate its antitumour effect.

\section{Materials and Methods}

2.1. Cell Culture. CNE and HEp-2 cells were cultured in RPMI-1640 medium containing $10 \%$ foetal bovine serum under the following conditions: $5 \% \mathrm{CO}_{2}, 37^{\circ} \mathrm{C}$, and wet saturation. At $80 \%$ confluency, the cells were passaged by transferring from one flask to two to three flasks, after treatment with $0.25 \%$ trypsin. Cells that were not tested immediately were frozen in the corresponding culture medium containing $10 \%$ DMSO, at $-70^{\circ} \mathrm{C}$.

2.2. Preparation of AgNPs. First, $80 \mathrm{~mL}$ of a $0.1 \mathrm{mM}$ AgNO3 solution was taken in a round-bottomed 3-mouth flask equipped with a condenser and mechanical stirrer and then heated to boiling while maintaining the backflow. Five millilitres of a $1 \%(\mathrm{w} / \mathrm{v})$ sodium citrate solution was added during vigorous stirring; the mixture was stirred and heated for another $30 \mathrm{~min}$. The reaction solution gradually changed from colourless to bright yellow after the addition of the sodium citrate solution. When the reaction was complete, heating was stopped, while stirring was maintained, to cool the solution to $20^{\circ} \mathrm{C}$. Deionised water was finally added to obtain a volume of of $100 \mathrm{~mL}$.

2.3. Preparation of $A g / C 225$. Boric acid buffer ( $\mathrm{pH} 9.0$ ) was added to the AgNP solution to maintain the $\mathrm{pH}$ at 7.9, under continuous shaking at $37^{\circ} \mathrm{C}$. Then, the reaction was blocked by adding $4 \%$ BSA solution $(400 \mu \mathrm{L})$, followed by the addition of $400 \mu \mathrm{L} \mathrm{C} 225$. The reaction mixture was stirred continuously for $30 \mathrm{~min}$ at $37^{\circ} \mathrm{C}$. Finally, the solution was centrifuged at $11,742 \times \mathrm{g}$ and $4^{\circ} \mathrm{C}$ for $1 \mathrm{~h}$; the supernatant was discarded and the appropriate amount of sterile deionised water was added to dissolve the precipitate.

2.4. Electron Microscopic Detection. A small amount of self-prepared AgNPs was added to anhydrous ethanol for ultrasonic dispersion for $15 \mathrm{~min}$ and then dripped onto a copper wire mesh with a carbon membrane to prepare the electron microscopy sample, which was observed under a transmission electron microscope (TEM).

In addition, cells were collected by centrifugation at $1,200 \times \mathrm{g}$ for $10 \mathrm{~min}$ and were immediately fixed with $2.5 \%$ glutaraldehyde (Sigma-Aldrich) in $0.1 \mathrm{M}$ phosphate buffer for $4 \mathrm{~h}$. Cells were fixed for $1.5 \mathrm{~h}$ using $2 \%$ osmic acid (SigmaAldrich) and rinsed with PBS five times. Then, they were dehydrated with $50,70,80,90,95$, and $100 \%$ acetone I for $10 \mathrm{~min}$ and with $100 \%$ acetone II and III for $40 \mathrm{~min}$. The 812 epoxy resin and acetone (Sigma-Aldrich) 1:1 mixed liquor was used for embedding and saturation for $1.5 \mathrm{~h}$. Pure resin was embedded and polymerised for $3 \mathrm{~h}$ at room temperature, for $12 \mathrm{~h}$ at $37^{\circ} \mathrm{C}$, for $12 \mathrm{~h}$ at $45^{\circ} \mathrm{C}$, and for $48 \mathrm{~h}$ at $60^{\circ} \mathrm{C}$. The embedded end was trimmed, sliced, and double-stained with uranium lead, as previously described [9] and then observed under a TEM (JEOL, JEM-1400).

2.5. Observation of Cell Morphology under an Inverted Microscope. The cells were grown to confluency for $24 \mathrm{~h}$; the culture medium in each culture flask was discarded. Then, either RPMI-1640 medium (negative control group) or $0.083 \sim 43.5 \mu \mathrm{g} / \mathrm{mL} \mathrm{Ag} / \mathrm{C} 225$ was added repetitively, followed by continuous culture of each group of cells for $48 \mathrm{~h}$. Cell morphology was then observed and photographed using an inverted microscope.

\subsection{Calculation of Cell Proliferation Inhibition Percentage and Half-Maximal Inhibitory Concentration (IC50). Cells were seeded in 96-well plates at a density of $4 \times 10^{3}$ cells per well and cell viability was determined after $48 \mathrm{~h}$ using the methyl thiazolyl tetrazolium (MTT) assay. To each well, $20 \mu \mathrm{L}$ of MTT stock solution $(5 \mathrm{mg} / \mathrm{mL})$ was added and $200 \mu \mathrm{L}$ DMSO was added after $4 \mathrm{~h}$ incubation at $37^{\circ} \mathrm{C}$. The absorbance was measured at a wavelength of $488 \mathrm{~nm}$ using a microplate reader (Bio-Rad, Hercules, USA). \\ The cell proliferation inhibition percentage was calculated according to the following formula:}

Inhibition percentage of experimental group (\%)

$$
=\left[\frac{(\text { OD value of negative control group - OD value of experimental group })}{\text { OD value of negative control group }}\right] \times 100 \% \text {. }
$$

The SPSS (Statistical Package for the Social Science) 17.0 was used to calculate IC50 with the Bliss method.
2.7. Cell Cycle Analysis. The cell cycle distribution of CNE and HEp-2 was performed mainly according to standard 
protocol $[10,11]$ via flow cytometry. To be specific, cells (5 $\times 10^{6}$ ) were treated with AgNPs and Ag/C225 (at 1/5 IC50) for $24 \mathrm{~h}$, after which they were collected, washed with cold phosphate buffered saline (PBS), and fixed in ice-cold 70\% ethanol. The samples were then stored at $-20^{\circ} \mathrm{C}$ for 24 to $48 \mathrm{~h}$. Before analysis, the cells were washed with cold PBS and then suspended in PBS solution containing 0.1\% Triton $\mathrm{X}$ and $30 \mathrm{mg} / \mathrm{mL}$ DNase-free RNase A (Sigma, St. Louis, MO, USA) for $30 \mathrm{~min}$ at $37^{\circ} \mathrm{C}$. Propidium iodide (PI) was added at a final concentration of $10 \mu \mathrm{g} / \mathrm{mL}$. The samples were then analysed using a FACSCalibur flow cytometer (BD Biosciences, Franklin Lakes, NJ, USA). Data were processed with ModFit LT software (Verity Software House, Topsham, ME, USA). Data for at least 5000 cells were collected for each sample. All experiments were repeated three times.

2.8. Western Blot. Western blotting was performed according to standard procedures $[12,13]$ using goat monoclonal antibodies against the following proteins: $\mathrm{Bax}, \mathrm{Bcl}-2$, and p21 (all from Santa Cruz Biotechnology, Dallas, TX, USA). The mouse monoclonal antibody against $\beta$-actin was from ZSGB-BIO OriGene (Beijing, China). Primary antibodies were used at dilution ratios recommended by the manufacturers. Horseradish peroxidase-conjugated secondary antibodies were used at a dilution of 1:5000.

2.9. Immunocytochemistry. Immunocytochemistry was performed as previously described [14]. Cells mounted on coverslips were fixed with cold acetone for $10 \mathrm{~min}$ and then incubated in a blocking buffer $(0.01 \mathrm{M}$ PBS with $2 \%$ goat serum, $1 \%$ bovine serum albumin, $0.1 \%$ gelatin, and $0.1 \%$ Triton X-100) for $30 \mathrm{~min}$ at room temperature. We used primary rabbit anti- $\boldsymbol{\gamma}$-H2AX (Cell Signaling Technology, Danvers, MA, USA), incubated at $4^{\circ} \mathrm{C}$ overnight, and subsequently incubated for $1 \mathrm{~h}$ at $25^{\circ} \mathrm{C}$ with the goat anti-rabbit IgG Dylight 594 secondary antibody (Thermo Scientific, Waltham, MA, USA). Nuclei were counterstained with 4,6-diamidino-2phenylindole (DAPI) (Sigma-Aldrich). Cells mounted on coverslips and incubated with PBS without primary antibodies served as negative controls (not shown). Cells were examined through an upright fluorescence microscope (Carl Zeiss, Jena, Germany).

2.10. Statistical Analysis. Data are expressed as mean \pm SD. Statistical software SPSS version 17 (SPSS, Chicago, USA) was used to carry out one-way ANOVA followed by a SNK test. The criterion of statistical difference was set at $P<0.05$.

\section{Results}

3.1. Characteristics of AgNPs and Ag/C225. The prepared AgNPs and Ag/C225 nanoparticles were light black powders, and they were suspended in a colloidal state with excellent dispersion. AgNPs showed no layered sedimentation at $4^{\circ} \mathrm{C}$ within $48 \mathrm{~h}$ and displayed slightly layered sedimentation after two weeks. The suspension could be restabilised after $1 \mathrm{~min}$ of ultrasound treatment. Composite material Ag/C225 showed no layered sedimentation at $4^{\circ} \mathrm{C}$ within $48 \mathrm{~h}$ and displayed slightly layered sedimentation after one week. The suspension could be restabilised after 1 min of ultrasound treatment.

After ultrasound dispersion, the prepared AgNPs were quasi circular with high electronic density and uniform size in distributed or aggregated clusters (Figure 1(a)), as observed under a TEM. After ultrasound dispersion, the prepared $\mathrm{Ag} / \mathrm{C} 225$ nanoparticles were almost circular with partial areas having high electronic density in distributed or aggregated clusters (Figure 1(b)), as observed under a TEM. No obvious morphological difference was observed between them.

\subsection{AgNPs and Ag/C225 Inhibited the Proliferation of CNE} and HEp-2 Cells. After a $24 \mathrm{~h}$ coincubation of CNE cells with $\mathrm{AgNPs}$ or $\mathrm{Ag} / \mathrm{C} 225$, morphological changes in cells were observed under a light microscope (Figure 2). The control CNE cells were in the shape of long shuttles with complete external forms, close layout, full neoplasm, evenness, and transparency and grew on the bottle wall. With increased density of AgNPs and Ag/C225, the CNE cell morphology changed from the dominant long shuttle to the dominant short shuttle and the cells were quasi oval, with widened cell spacing and decreased cell density. Neoplasm showed decreased transparency, enhanced refraction degree, and decreased cell adherence ability; some cells shrunk, separated from the surrounding ones, and floated at the top of the culture solution (Figures 2(e) and 2(f)). MTT assay revealed that AgNPs and $\mathrm{Ag} / \mathrm{C} 225$ inhibited CNE cell proliferation in a dose-dependent manner. The half inhibiting densities (IC50) of AgNP- and Ag/C225-treated CNE cells were $9.909 \mu \mathrm{g} / \mathrm{mL}$ and $14.25 \mu \mathrm{g} / \mathrm{mL}$, respectively (Table 1 and Figure $2(\mathrm{~g})$ ), while the $1 / 5 \mathrm{IC} 50$ was $1,982 \mu \mathrm{g} / \mathrm{mL}$ and $2.90 \mu \mathrm{g} / \mathrm{mL}$, respectively.

After a 24-h coincubation of HEp-2 cells and AgNPs, morphological changes in cells were observed under a light microscope (Figure 3). The HEp-2 cells in the control group were in the shape of long shuttles with complete external form, close layout, full cytoplasm, evenness, and transparency and grew on the bottle wall. With increased density of AgNPs and $\mathrm{Ag} / \mathrm{C} 225$, the HEp-2 cell morphology changed from dominant long shuttle to dominant short shuttle and the cells were oval shaped, with decreased cell density, decreased transparency, enhanced refraction degree, and decreased cellular adherence ability; some cells shrunk, separated from surrounding ones, and floated at the top of the culture solution (Figures 3(e) and 3(f)). AgNPs and Ag/C225 inhibited HEp-2 cell proliferation in a dose-dependent manner. The IC50 values for AgNPs and Ag/C225 against HEp-2 cells were $2.243 \mu \mathrm{g} / \mathrm{mL}$ and $2.206 \mu \mathrm{g} / \mathrm{mL}$, respectively (Table 2 and Figure $3(\mathrm{~g})$ ), showing no obvious difference between them.

3.3. Influence of AgNPs and Ag/C225 on the CNE and HEp-2 Cell Cycles. After a 24-h coincubation of AgNPs and Ag/C225 (at 1/5 IC50) with CNE cells, we used flow cytometry (FCM) to detect cell cycle distributions (Figures 4(a)-4(c)). In the AgNP- and Ag/C225-treated groups, cells at the G0/G1 stage accounted for $52.78 \pm 6.42 \%$ and $75.54 \pm 6.26 \%$, respectively, with a statistically significant difference $(P<0.05$ for both) compared to their respective control groups. There was also a statistically significant difference between the G0/G1 cell 


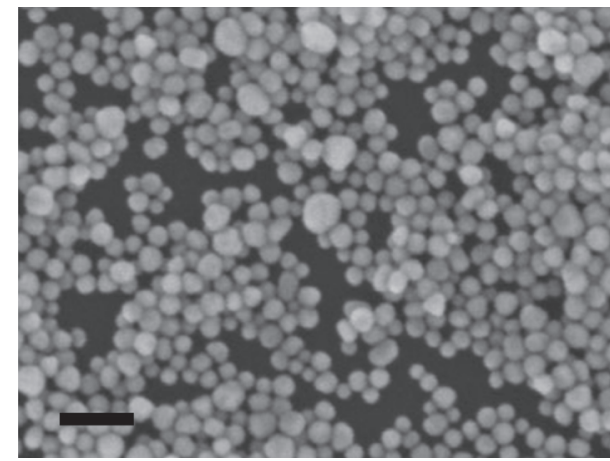

$\mathrm{Mag}=200.00 \mathrm{KX}$
Signal A = InLens

(a)

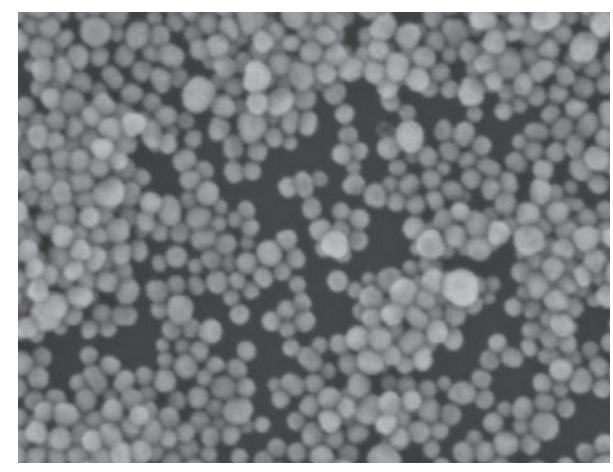

$\mathrm{EHT}=5.00 \mathrm{kV}$

(b)

Figure 1: Transmission electron microscopy image of (a) AgNPs and (b) Ag/C225, indicating excellent dispersion and uniformity. Most of the AgNPs and Ag/C225 were spherical or nearly spherical. Scale bar: $50 \mathrm{~nm}$.

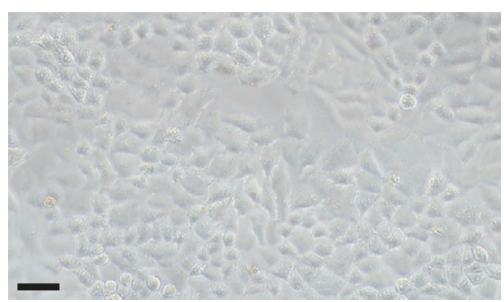

(a)

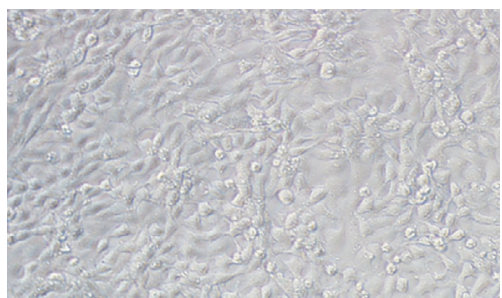

(d)

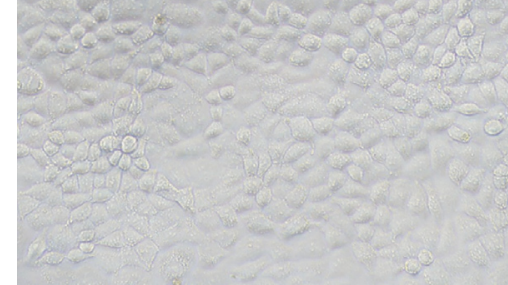

(b)

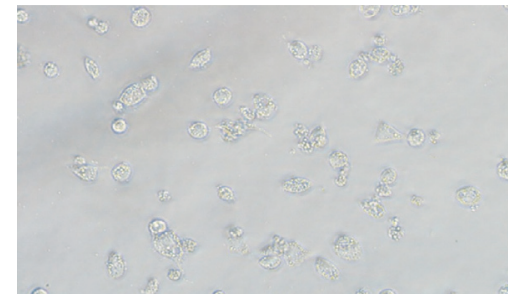

(e)

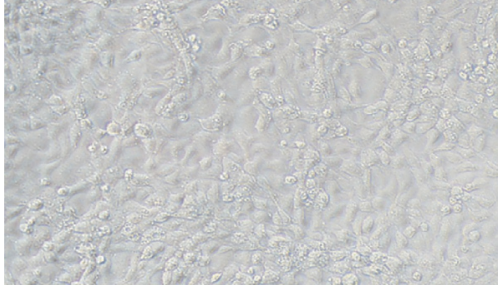

(c)

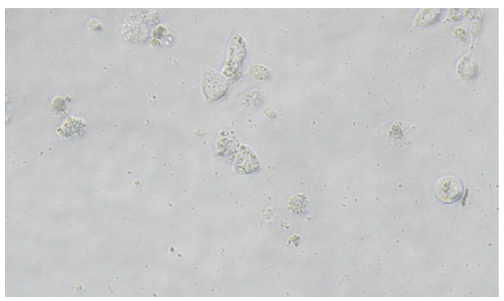

(f)

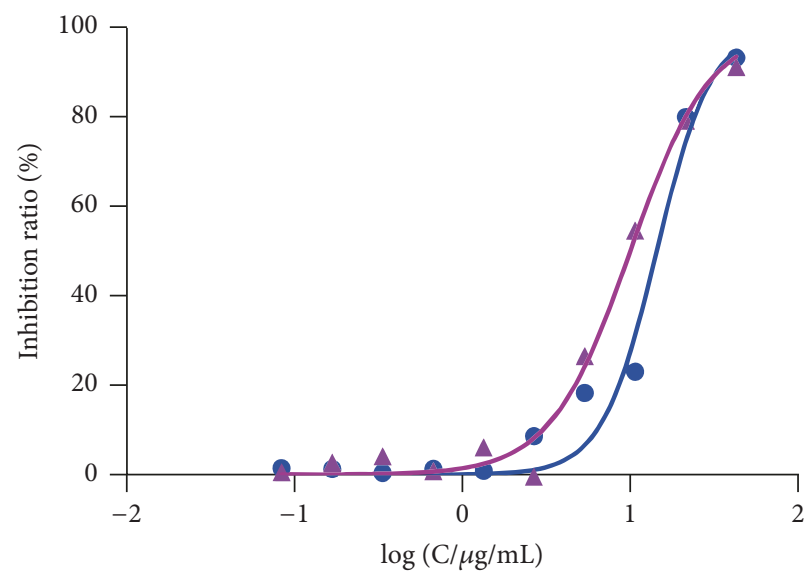

- AgNPs

A Ag/C225

(g)

Figure 2: CNE cell morphology after Ag/C225 treatment. (a) Control group. Scale bar: $100 \mu \mathrm{m}$. (b-f) Ag/C225 treatment groups $(0.083-43.5 \mu \mathrm{g} / \mathrm{mL} \mathrm{Ag} / \mathrm{C} 225)$. (g) Corresponding inhibition ratios for AgNP treatment and Ag/C225 treatment at different concentrations in CNE cells $(n=5)$. 
TABLE 1: Corresponding inhibition ratios of AgNP treatment and Ag/C225 treatment at different concentrations in CNE cells $(n=5)$.

\begin{tabular}{lcr}
\hline Treating concentration $(\mu \mathrm{g} / \mathrm{mL})$ & \multicolumn{2}{c}{ Inhibition ratio $(\%)$} \\
\hline 0 & 0 & 0 \\
0.083 & $1.44 \pm 0.028$ & $0.51 \pm 0.031$ \\
0.166 & $1.29 \pm 0.033$ & $2.73 \pm 0.133$ \\
0.332 & $0.38 \pm 0.026$ & $4.09 \pm 0.936$ \\
0.6641 & $1.29 \pm 0.211$ & $5.77 \pm 1.309$ \\
1.3281 & $0.91 \pm 0.208$ & $6.13 \pm 2.687$ \\
2.6563 & $8.62 \pm 1.141$ & $6.34 \pm 1.233$ \\
5.3125 & $18.31 \pm 3.201$ & $26.58 \pm 3.199$ \\
10.625 & $23.00 \pm 4.127$ & $54.60 \pm 3.803$ \\
21.25 & $80.03 \pm 4.318$ & $79.22 \pm 3.422$ \\
42.50 & $93.27 \pm 5.239$ & $91.23 \pm 6.102$ \\
\hline
\end{tabular}

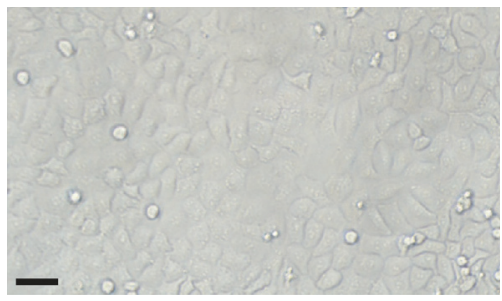

(a)

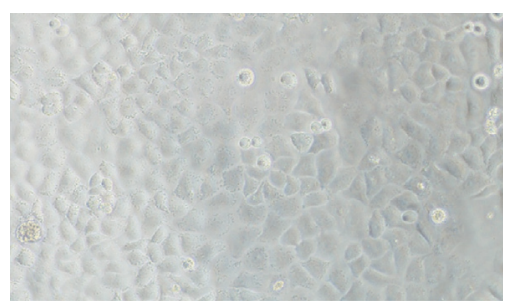

(d)

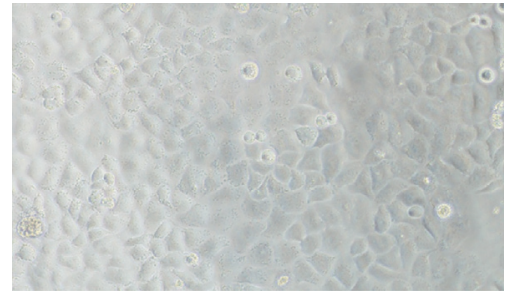

(b)

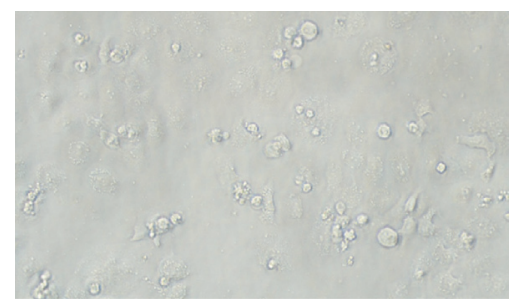

(e)

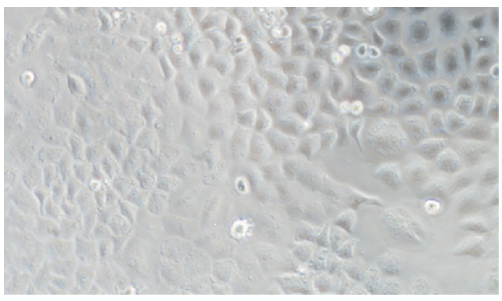

(c)

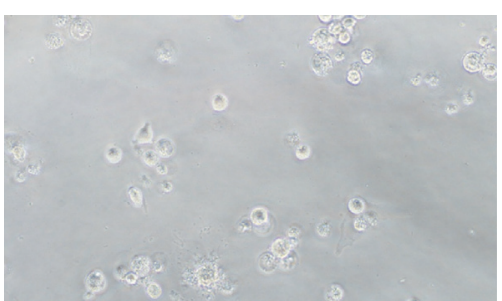

(f)

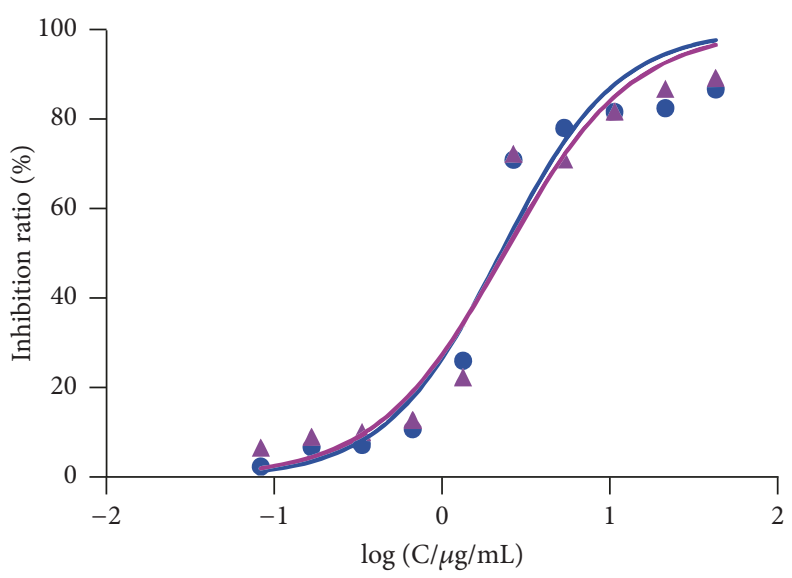

- AgNPs

$\Delta \mathrm{Ag} / \mathrm{C} 225$

(g)

Figure 3: HEp-2 cell morphology after Ag/C225 treatment. (a) Control group. Scale bar: $100 \mu m$. (b-f) Ag/C225 treatment groups $(0.083-43.5 \mu \mathrm{g} / \mathrm{mL} \mathrm{Ag} / \mathrm{C} 225)$. (g) Corresponding inhibition ratios of AgNP treatment and Ag/C225 treatment at different concentrations in HEp-2 cells $(n=5)$. 
TABLE 2: Corresponding inhibition ratios of AgNP treatment and Ag/C225 treatment at different concentrations in HEp-2 cells $(n=5)$.

\begin{tabular}{lcr}
\hline Treating concentration $(\mu \mathrm{g} / \mathrm{mL})$ & \multicolumn{2}{c}{ Inhibition ratio (\%) } \\
\hline 0 & 0 & 0 \\
0.083 & $2.57 \pm 0.015$ & $6.83 \pm 0.031$ \\
0.166 & $6.86 \pm 0.032$ & $9.19 \pm 0.133$ \\
0.332 & $6.35 \pm 0.061$ & $10.31 \pm 0.936$ \\
0.6641 & $10.91 \pm 1.102$ & $12.92 \pm 1.309$ \\
1.3281 & $26.10 \pm 2.454$ & $22.48 \pm 2.687$ \\
2.6563 & $70.96 \pm 6.208$ & $72.30 \pm 2.133$ \\
5.3125 & $78.06 \pm 5.727$ & $71.06 \pm 3.199$ \\
10.625 & $81.62 \pm 6.706$ & $81.74 \pm 3.803$ \\
21.25 & $82.48 \pm 5.118$ & $86.83 \pm 3.422$ \\
42.50 & $86.64 \pm 7.121$ & $89.19 \pm 6.102$ \\
\hline
\end{tabular}

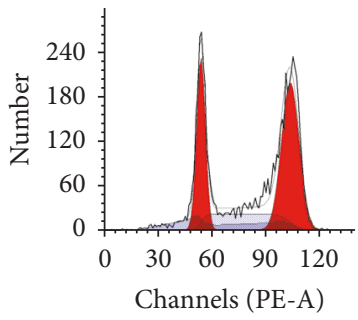

(a)

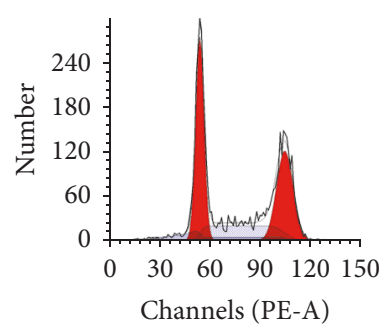

(e)

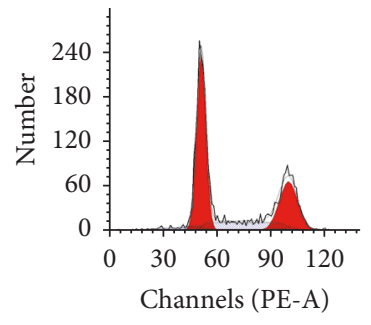

(b)

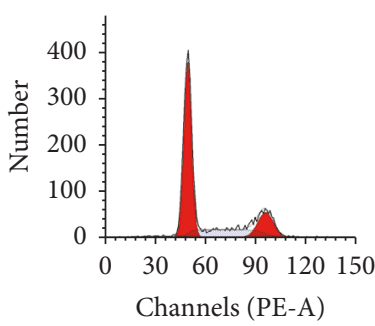

(f)

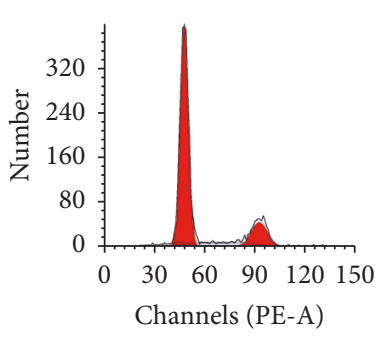

(c)

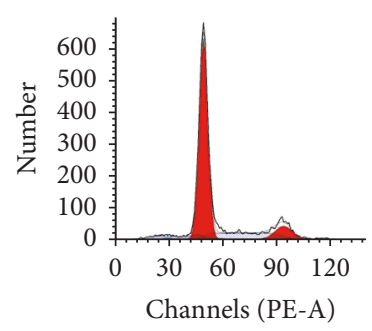

(g)

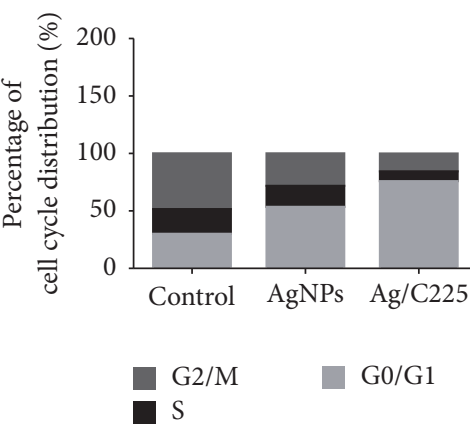

(d)

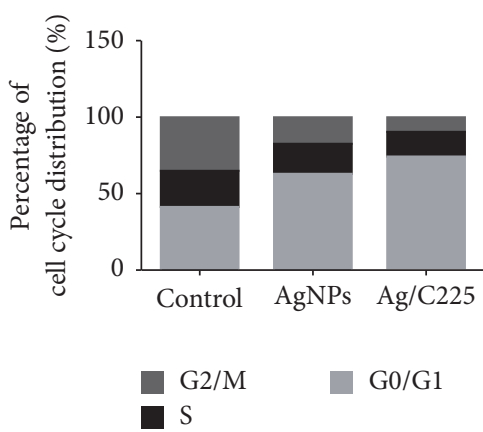

(h)

Figure 4: (a-c) Cell cycle analysis in CNE cells in (a) control, (b) AgNP-treated, and (c) Ag/C225-treated groups. (d) Quantitative analysis of CNE cells $(n=3)$. (e-g) Cell cycle analysis of HEp-2 cells in (e) control, (f) AgNP-treated, and (g) Ag/C225-treated groups. (h) Quantitative analysis of HEp-2 cells $(n=3)$.

numbers of the two treated groups $(P<0.05)$. The $\mathrm{G} 2 / \mathrm{M}$ stage cell percentages in the control group, the AgNPs, and the $\mathrm{Ag} / \mathrm{C} 225$ processing groups were $49.23 \pm 5.31 \%, 28.66 \pm$ $2.36 \%$, and $15.88 \pm 2.20 \%$, respectively; $S$ stage percentages were $21.78 \pm 2.01 \%, 18.56 \pm 1.42 \%$, and $8.57 \pm 1.15 \%$, respectively. The differences in these values were statistically significant (Figure 4(d)). S stage elimination had an even more marked effect in the Ag/C225-treated group $(P<0.05)$.

After a $24 \mathrm{~h}$ coincubation of AgNPs or Ag/C225 (at 1/5 IC50) with HEp-2 cells, we used FCM to assess cell cycle distributions (Figures 4(e)-4(g)). In the AgNP- and $\mathrm{Ag} / \mathrm{C} 225$-treated groups, G0/G1 stage cell percentages were $62.59 \pm 5.91 \%$ and $74.00 \pm 4.12 \%$, respectively; these values were significantly higher than those of the control group with $40.53 \pm 4.26 \%(P<0.05)$, showing that G0/G1 stage was retarded. G2/M stage cell percentages in the control group

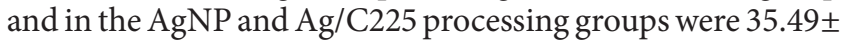
$3.08 \%, 17.49 \pm 1.98 \%$, and $9.65 \pm 1.56 \%$, respectively, with the percentage for S stage being $23.98 \pm 2.14 \%, 19.92 \pm 1.20 \%$, and $16.35 \pm 1.18 \%$, respectively. Although the decrease in the 


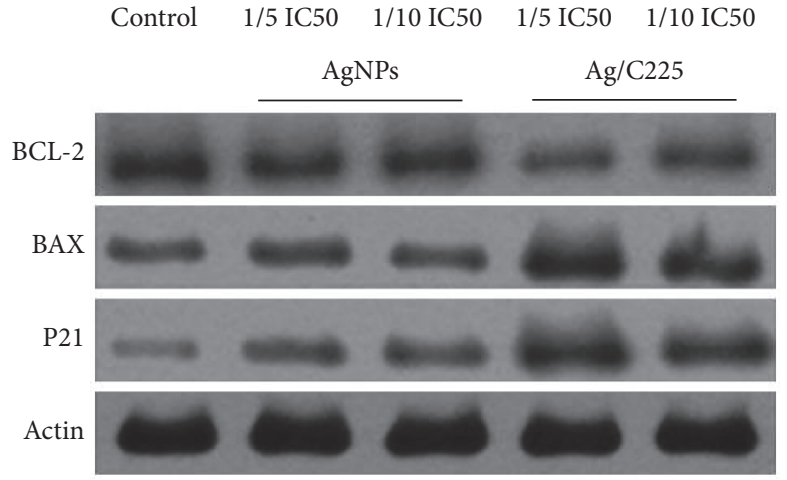

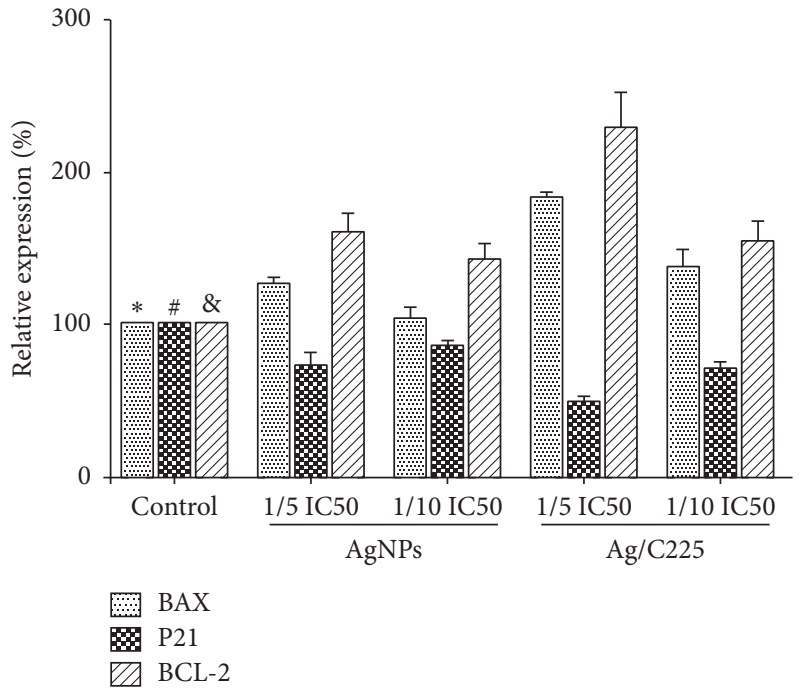

(b)

Figure 5: Expression of BCL-2, BAX, and P21 in CNEs treated with AgNPs and Ag/C225. (a) Western blots and (b) quantitative analysis from three independent experiments $\left({ }^{*} P<0.05\right.$ compared with all treated groups in Bax expression; ${ }^{*} P<0.05$ compared with all treated groups in P21 expression; ${ }^{\&} P<0.05$ compared with all treated groups in BCL-2 expression).

percentage of cells in the $S$ stage was minimal, there were statistically significant differences $(P<0.05)$ among the three groups (Figure 4(h)).

\subsection{Ag and Ag/C225 Effects on Cell Apoptosis-Related Protein} Expression. As shown in Figure 5, Ag/C225 (at 1/5 the IC50 value) downregulated Bcl-2 and upregulated $\mathrm{Bax}$ and $\mathrm{p} 21$. All these changes were the highest at $4 \mathrm{~h}$ posttreatment with $\mathrm{Ag}$ or $\mathrm{Ag} / \mathrm{C} 225$. The inhibitory effect in the $\mathrm{Ag} / \mathrm{C} 225$ group outperformed that in the AgNP group, and within the group, the 1/5 IC50 dosage group outperformed the 1/10 IC50 dosage group.

\subsection{Ag/C225 Could Be Absorbed by CNE Cells and Ag/C225} Enhanced the Cytotoxicity Induced by X-Irradiation. According to TEM, endocytosed $\mathrm{Ag} / \mathrm{C} 225$ was mainly located in CNE cytoplasm, Ag/C225 particle clusters were observed in partial inclusion bodies, and inclusion bodies taking up $\mathrm{Ag} / \mathrm{C} 225$ were observed in neighbouring cell membranes, indicating that cells absorbed $\mathrm{Ag} / \mathrm{C} 225$ nanoparticles by endocytosis (Figure 6).

The effects of $\mathrm{Ag} / \mathrm{C} 225$ on the cytotoxicity of X-ray irradiation in CNE cells were investigated using immunocytochemistry. Cells were irradiated with different doses of X-rays and then incubated with $2.418 \mu \mathrm{g} / \mathrm{mL} \mathrm{Ag}$ and $1.818 \mu \mathrm{g} / \mathrm{mL} \mathrm{Ag} / \mathrm{C} 225$ (1/5 the IC50 value) for $24 \mathrm{~h}$. These concentrations of $\mathrm{Ag}$ and $\mathrm{Ag} / \mathrm{C} 225$ were not significantly cytotoxic alone at the exposure time used (Figure 1 and Table 1). Immunofluorescent detection revealed that the $\mathrm{Ag} / \mathrm{C} 225$-treated X-ray-irradiated group showed increased $\gamma$ $\mathrm{H} 2 \mathrm{AX}$ focal point number, compared to the X-ray-irradiated group, indicating that $\mathrm{Ag} / \mathrm{C} 225$ in conjunction with X-rays could enhance the effect of CNE cell DNA double strand break (DSB; Figure 7).

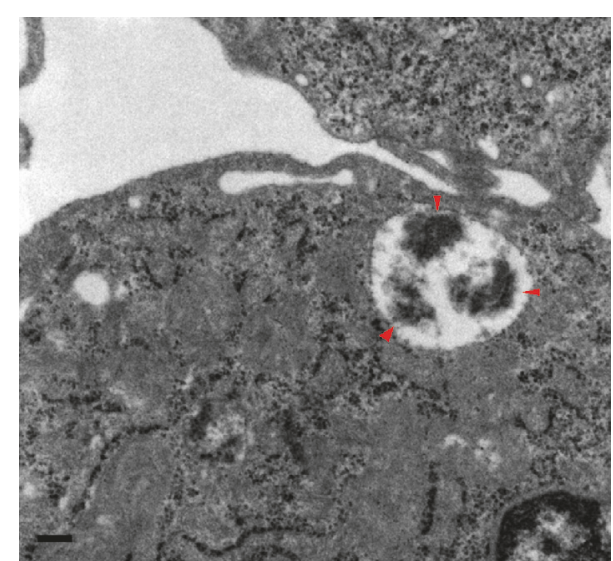

FIgURE 6: Transmission electron microscopy image shows that cell absorbs Ag/C225 particles by endocytosis. Scale bar: $0.2 \mu \mathrm{m}$. Red arrowheads indicate $\mathrm{Ag} / \mathrm{C} 225$ particles.

\section{Discussion}

With the development of nanotechnology, many metal nanomaterials have been widely used in the industry, medicine, and life sciences fields. Owing to their small size, nanomaterials can stay inside cells after their entry across the cell membranes or even enter the nucleus through holes in the nuclear membrane [15]. Nanotechnology has the potential of being widely applied in tumour diagnosis and treatment. At present, many nanoparticles have been used for tumour imaging as well as for animal and human tests. In previous clinical practice, heavy metal-based nanoparticles like nano$\mathrm{Au}$ were considered as potential radiosensitisers. Naked gold nanoparticles (GNPs) can accumulate in tumour tissues 


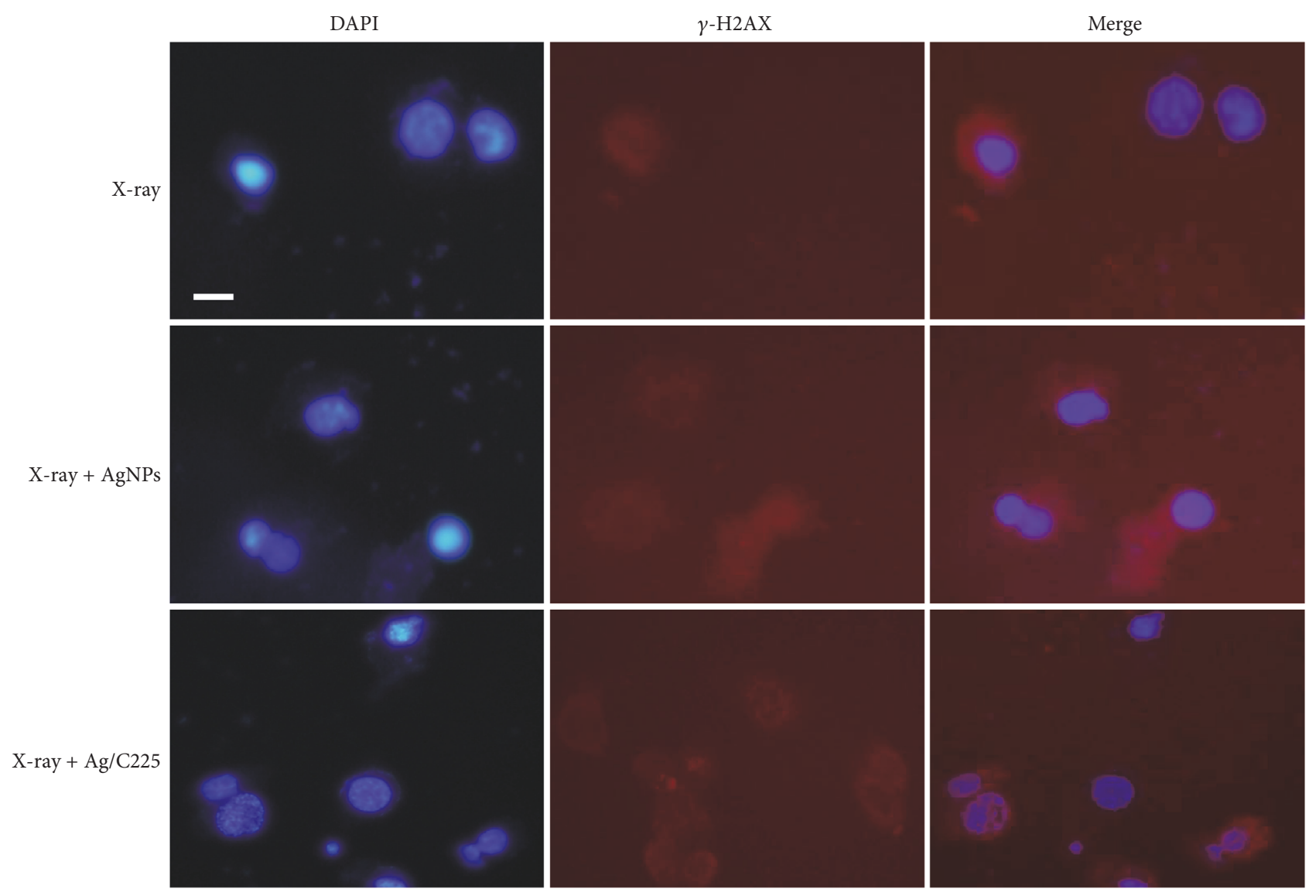

Figure 7: Foci of $\gamma$-H2AX treated with AgNPs or Ag/C225 along with X-ray irradiation. Scale bar: $10 \mu \mathrm{m}$.

through passive targeting and be used as a radiosensitiser to kill tumours.

In this research, we first successfully prepared $20 \mathrm{~nm}$ AgNPs and Ag/C225 particles and primarily characterised them using electron microscopy. According to ELISA detection in previous studies, C225 successfully couples with AgNPs [16]. In subsequent experiments, we chose two lines of neck tumour cells, namely, human nasopharyngeal carcinoma cells (CNE) and human laryngeal carcinoma cells (HEp-2), for primary in vitro experiments. The influence of different densities upon growth and proliferation was observed using light microscopy; cell proliferation was also monitored by MTT assay and IC50 values were calculated. The HEp-2 cell line was more sensitive to Ag/NPs and $\mathrm{Ag} / \mathrm{C} 225$ than the CNE cell line was. The IC50s of AgNPs were $2.243 \mu \mathrm{g} / \mathrm{mL}$ and $2.206 \mu \mathrm{g} / \mathrm{mL}$ in HEp-2 cells, while those for CNE cells were $14.25 \mu \mathrm{g} / \mathrm{mL}$ and $9.909 \mu \mathrm{g} / \mathrm{mL}$. These results show that there was no obvious difference between $\mathrm{Ag} / \mathrm{NPs}$ and $\mathrm{Ag} / \mathrm{C} 225$ in inhibiting HEp-2 proliferation $(P>$ 0.05 , Figure $3(\mathrm{~g}))$. According to the IC50 value calculated from the MTT results, 1/5 IC50 Ag/NPs and Ag/C225 were used for $24 \mathrm{~h}$ coincubation with CNE and HEp-2 cells. FCM showed that both AgNPs and Ag/C225 (1) induced cells to enter G0/G1 stage, inhibited growth, and induced damaged cells to enter into apoptosis state and (2) induced CNE and HEp-2 cells to enter into $S$ stage less and decreased the radiation resistance of the cells. The Ag/C225 group exhibited considerably higher $S$ stage elimination than the AgNPs group did (Figure 4). The western blot method was used to detect the expression of proteins related to cell apoptosis and cell cycle within each group. Protein expression semiquantification showed that, compared with the CNE cell control group, AgNP- and Ag/C225-treated groups showed increased expression of apoptotic proteins Bax and P21 and decreased expression of the antiapoptotic protein $\mathrm{Bcl}-2$, with statistically significant differences among the three groups $(P<0.05$, Figure 5).

As there is no obvious difference between AgNPs and $\mathrm{Ag} / \mathrm{C} 225$ in inhibiting HEp-2 proliferation, in future radioactive sensitising-related experiment, we will use the CNE cell line as the experimental cell line. Electron microscopy showed that Ag/C225 could be absorbed by CNE cells (Figure 6), and the immunofluorescence assays revealed the $\gamma$-H2AX focal points of different groups of cells under the same energy and dosage of X-rays (Figure 7), hinting at DNA DSB. Fluorescence microscopy revealed that the $\gamma-\mathrm{H} 2 \mathrm{AX}$ focal points increased considerably in AgNP- and Ag/C225treated groups, compared to that of the control group, with $\mathrm{Ag} / \mathrm{C} 225$ showing a higher effect. We deduce that AgNPs and $\mathrm{Ag} / \mathrm{C} 225$ possibly inhibit DNA repair by controlling the expression of DNA repair proteins, thus enhancing the radiation sensitivity of CNE cells. 
Radioactive rays can kill cancer cells because they can cause DNA damage to tumour cells, while nonhomologous end connection serves as the main repair mechanism in DSB repair caused by ionised radiation. This process requires the involvement of Ku70, Ku80, DNA ligase IV, and accessory proteins. Therefore, blocking or reducing the binding of Ku to broken DNA strands can influence the radiation sensitivity of cancer cells [17-20]. Chen et al. indicated that Ku80 expression was negatively correlated with radiation sensitivity in low dosage radiotherapy [21], and $\mathrm{Ku}$ protein expression could be used for predicting the radiation sensitivity of cells [22-26]. In tumour radiotherapy, cancers can be treated via energy accumulation that will cause DNA DSB in cells. At present, there are two known mechanisms involved in the repair of DNA DSB: regrouping repair and nonhomologous end connection. Of these, homologous matching serves as a key step in regrouping repair, and Rad51 [27-30] plays a crucial role therein as a necessary enzyme for catalysing homologous matching. Rad51 and Ku proteins represent DSB repair mechanisms for homologous regrouping repair and nonhomologous end connection. Our further studies will focus on investigating whether DNA repair-related proteins are affected by $\mathrm{Ag} / \mathrm{NP}$ or $\mathrm{Ag} / \mathrm{C} 225$ treatment to demonstrate that $\mathrm{Ag} / \mathrm{NPs}$ and $\mathrm{Ag} / \mathrm{C} 225$ can function as radiosensitisers.

\section{Conclusion}

AgNPs and Ag/C225 can exert an inhibiting effect on human nasopharyngeal carcinoma cell line $\mathrm{CNE}$ and laryngeal carcinoma cell line HEp-2 by influencing the cell cycle. Moreover, $\mathrm{Ag} / \mathrm{C} 225$ can enhance the cytotoxicity induced by X-ray irradiation.

\section{Conflicts of Interest}

The authors declare that they have no conflicts of interest.

\section{Authors' Contributions}

Yan Zhang and Hong Lu contributed equally to this paper.

\section{Acknowledgments}

This work was supported by the grants from National Natural Science Foundation of China (81301971) and General Projects of Tianjin Medical University (Grant no. 2015kyzm02).

\section{References}

[1] T. Kong, J. Zeng, X. P. Wang et al., "Enhancement of radiation cytotoxicity in breast-cancer cells by localized attachment of gold nanoparticles," Small, vol. 4, no. 9, pp. 1537-1543, 2008.

[2] P. V. AshaRani, G. L. K. Mun, M. P. Hande, and S. Valiyaveettil, "Cytotoxicity and genotoxicity of silver nanoparticles in human cells," ACS Nano, vol. 3, no. 2, pp. 279-290, 2009.

[3] R. Xu, J. Ma, X. Sun et al., "Ag nanoparticles sensitize IR-induced killing of cancer cells," Cell Research, vol. 19, no. 8, pp. 1031-1034, 2009.
[4] H. Vermund, "The significance of the tumor bed reactions in the radiation treatment of malignant tumors," The American Journal of Roentgenology, Radium Therapy, and Nuclear Medicine, vol. 82, pp. 678-687, 1959.

[5] R. Rajagopalan, T. V. Kagiya, and C. K. K. Nair, "Radiosensitizer sanazole (AK-2123) enhances $\gamma$-radiation-induced apoptosis in murine fibrosarcoma," Journal of Radiation Research, vol. 44, no. 4, pp. 359-365, 2003.

[6] A. E. M. Mahdy, J. C. Cheng, J. Li et al., "Acid ceramidase upregulation in prostate cancer cells confers resistance to radiation: AC inhibition, a potential radiosensitizer," Molecular Therapy, vol. 17, no. 3, pp. 430-438, 2009.

[7] R. Murata, M. Tsujitani, and M. R. Horsman, "Enhanced local tumour control after single or fractionated radiation treatment using the hypoxic cell radiosensitizer doranidazole," Radiotherapy and Oncology, vol. 87, no. 3, pp. 331-338, 2008.

[8] J. A. Bonner, P. M. Harari, J. Giralt et al., "Radiotherapy plus cetuximab for squamous-cell carcinoma of the head and neck," The New England Journal of Medicine, vol. 354, no. 6, pp. 567578, 2006.

[9] G. Gan, H. Lv, W. Xie, and R. Zhou, "Morphological identification and development of neurite in Drosophila ventral nerve cord neuropil," PLoS ONE, vol. 9, no. 8, Article ID e105497, 2014.

[10] M. Duda, A. Gasińska, and E. Gregoraszczuk, "Flow cytometric cell cycle analysis of two subpopulations of porcine granulosa cells," Experimental and Clinical Endocrinology \& amp; Diabetes, vol. 107, no. 03, pp. 203-207, 1999.

[11] Y. Wang, C. Gao, Y. Zhang et al., "Visfatin stimulates endometrial cancer cell proliferation via activation of PI3K/Akt and MAPK/ERK1/2 signalling pathways," Gynecologic Oncology, vol. 143, no. 1, pp. 168-178, 2016.

[12] J. Kaur and A. K. Bachhawat, "A modified Western blot protocol for enhanced sensitivity in the detection of a membrane protein," Analytical Biochemistry, vol. 384, no. 2, pp. 348-349, 2009.

[13] P. Sun, S. Wei, X. Wei et al., "Anger emotional stress influences VEGF/VEGFR2 and its induced PI3K/AKT/mTOR signaling pathway," Neural Plasticity, vol. 2016, Article ID 4129015, 12 pages, 2016.

[14] J. Ding, Z. Zhao, C. Wang et al., "Bioluminescence imaging of transplanted human endothelial colony-forming cells in an ischemic mouse model," Brain Research, vol. 1642, pp. 209-218, 2016.

[15] B. Kang, M. A. Mackey, and M. A. El-Sayed, "Nuclear targeting of gold nanoparticles in cancer cells induces DNA damage, causing cytokinesis arrest and apoptosis," Journal of the American Chemical Society, vol. 132, no. 5, pp. 1517-1519, 2010.

[16] D. Zhao, X. Sun, J. Tong et al., "A novel multifunctional nanocomposite $\mathrm{C} 225$-conjugated $\mathrm{Fe}_{3} \mathrm{O}_{4} / \mathrm{Ag}$ enhances the sensitivity of nasopharyngeal carcinoma cells to radiotherapy," Acta Biochimica et Biophysica Sinica, vol. 44, no. 8, pp. 678-684, 2012.

[17] F. Cui, J. Li, A. Ding et al., "Conditional QTL mapping for plant height with respect to the length of the spike and internode in two mapping populations of wheat," Theoretical and Applied Genetics, vol. 122, no. 8, pp. 1517-1536, 2011.

[18] E. Weterings and D. J. Chen, "The endless tale of nonhomologous end-joining," Cell Research, vol. 18, no. 1, pp. 114124, 2008.

[19] J. Mi, J. Dziegielewski, E. Bolesta, D. L. Brautigan, and J. M. Larner, "Activation of DNA-PK by ionizing radiation is mediated by protein phosphatase 6," PLoS ONE, vol. 4, no. 2, Article ID e4395, 2009. 
[20] Z. Shao, A. J. Davis, K. R. Fattah et al., "Persistently bound Ku at DNA ends attenuates DNA end resection and homologous recombination," DNA Repair, vol. 11, no. 3, pp. 310-316, 2012.

[21] H. Chen, Y. Bao, L. Yu, R. Jia, W. Cheng, and C. Shao, "Comparison of cellular damage response to low-dose-rate125I seed irradiation and high-dose-rate gamma irradiation in human lung cancer cells," Brachytherapy, vol. 11, no. 2, pp. 149-156, 2012.

[22] E. Rass, A. Grabarz, P. Bertrand, and B.-S. Lopez, "Double Strand Break Repair, one mechanism can hide another: Alternative non-homologous end joining," Cancer/Radiotherapie, vol. 16, no. 1, pp. 1-10, 2012.

[23] G. Y. Ku and D. H. Ilson, "Role of neoadjuvant therapy for esophageal adenocarcinoma," Surgical Oncology Clinics of North America, vol. 18, no. 3, pp. 533-546, 2009.

[24] C. Foged, "Subunit vaccines of the future: the need for safe, customized and optimized particulate delivery systems," Therapeutic Delivery, vol. 2, no. 8, pp. 1057-1077, 2011.

[25] B. L. Mahaney, K. Meek, and S. P. Lees-Miller, "Repair of ionizing radiation-induced DNA double-strand breaks by nonhomologous end-joining," Biochemical Journal, vol. 417, no. 3, pp. 639-650, 2009.

[26] G. Cenci, L. Ciapponi, and M. Gatti, "The mechanism of telomere protection: a comparison between Drosophila and humans," Chromosoma, vol. 114, no. 3, pp. 135-145, 2005.

[27] S. G. Kuznetsov, D. C. Haines, B. K. Martin, and S. K. Sharan, "Loss of Rad51c leads to embryonic lethality and modulation of Trp53-dependent tumorigenesis in mice," Cancer Research, vol. 69, no. 3, pp. 863-872, 2009.

[28] I. Demuth and M. Digweed, "The clinical manifestation of a defective response to DNA double-strand breaks as exemplified by Nijmegen breakage syndrome," Oncogene, vol. 26, no. 56, pp. 7792-7798, 2007.

[29] S. Surade and T. L. Blundell, "Structural biology and drug discovery of difficult targets: the limits of ligandability," Chemistry and Biology, vol. 19, no. 1, pp. 42-50, 2012.

[30] N. Suwaki, K. Klare, and M. Tarsounas, "RAD51 paralogs: roles in DNA damage signalling, recombinational repair and tumorigenesis," Seminars in Cell and Developmental Biology, vol. 22, no. 8, pp. 898-905, 2011. 

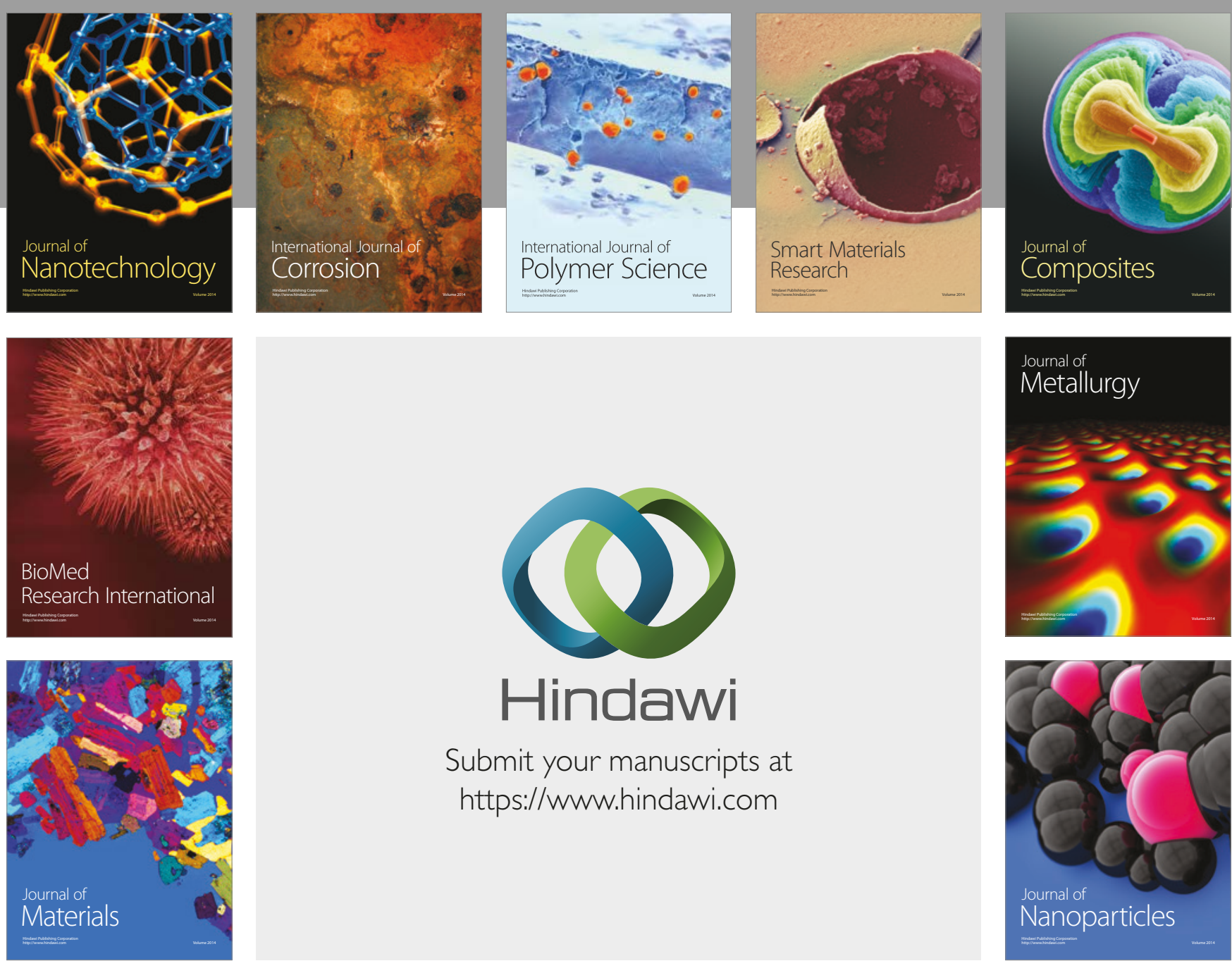

\section{Hindawi}

Submit your manuscripts at

https://www.hindawi.com
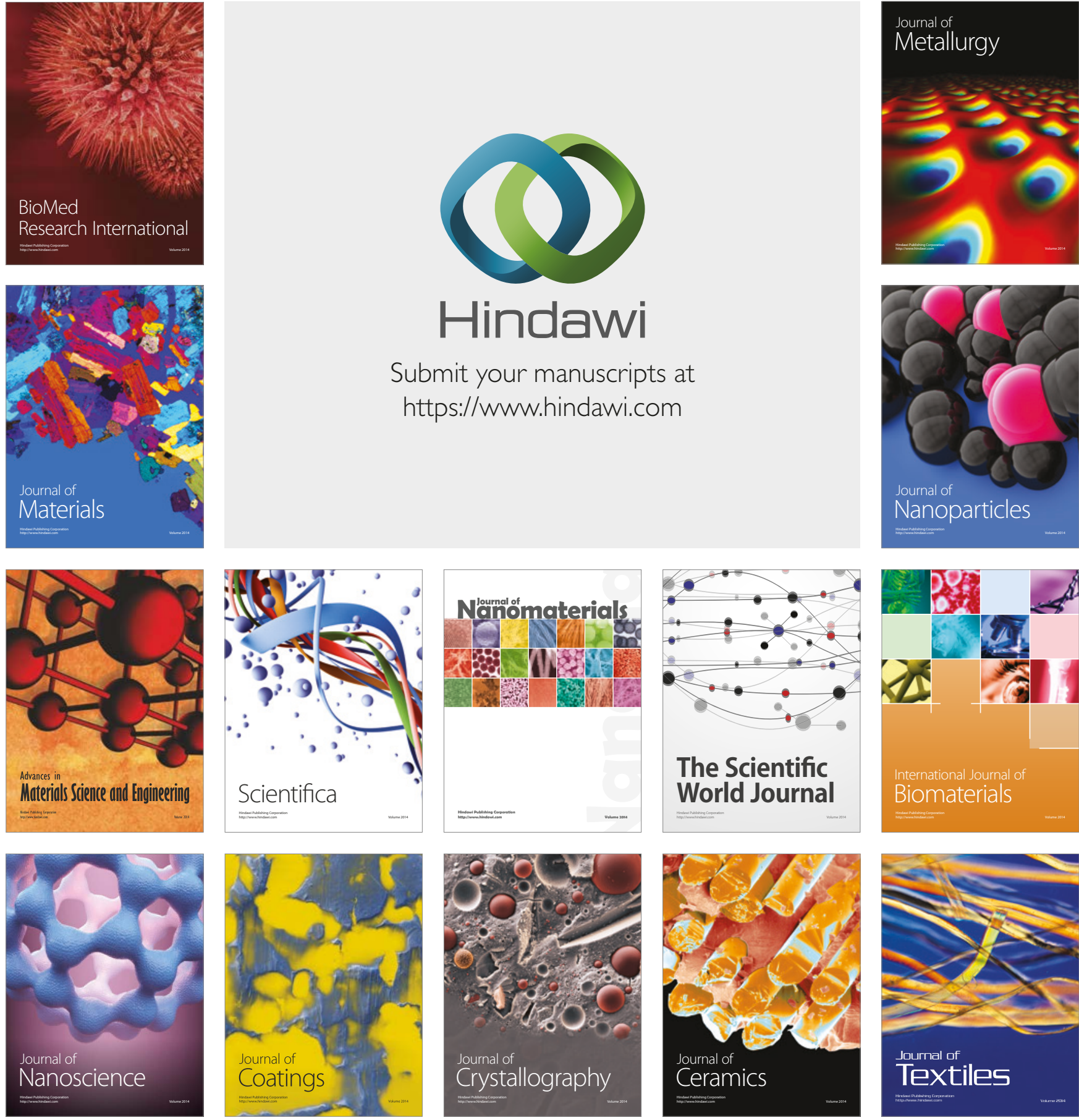

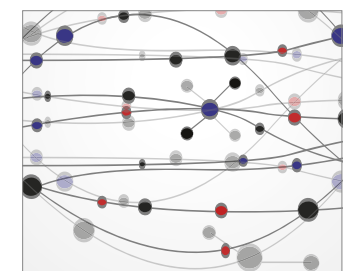

The Scientific World Journal
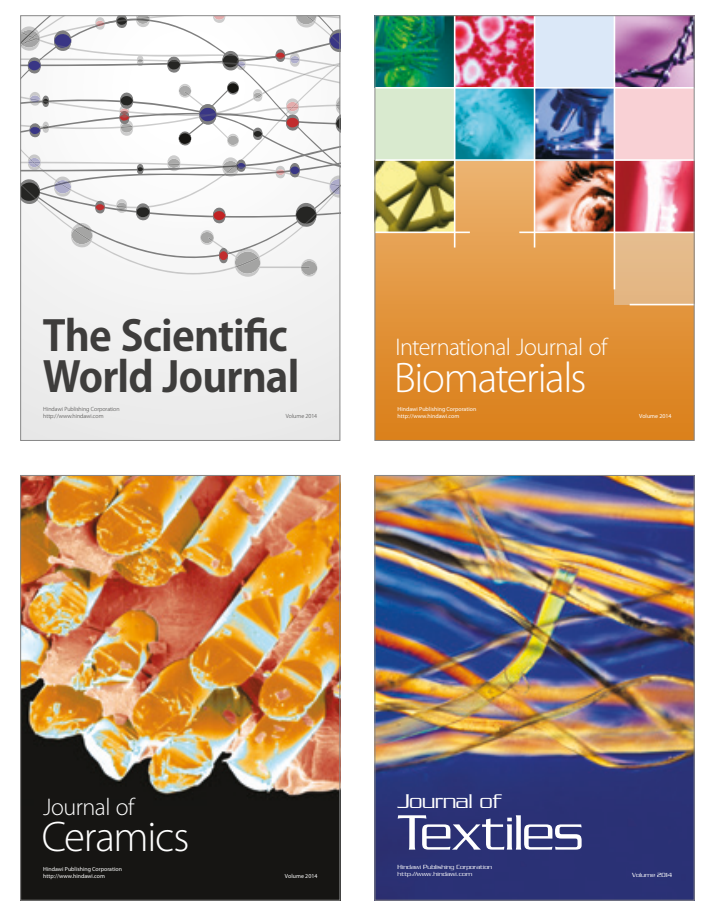